\title{
Determining the Optimal Geometry of RBS Connection for enhancement of Seismic Behavior of Steel Moment Frames
}

\author{
Hadi Einabadi, Vahidreza Kalatjari and hossein khosravi* \\ Department of Civil Engineering, Neyshabur Branch, Islamic Azad University, Neyshabur, Iran \\ Hadieinabadi@yahoo.com \\ Department of Civil Engineering, Shahrood University, Shahrood, Iran \\ V.kalatjari@gmail.com \\ YoungResearchers and Elite Club, Neyshabur Branch, Islamic Azad University, Neyshabur, Iran \\ wwwkhosravi@yahoo.com
}

\begin{abstract}
In a RBS connection, the stress concentration is being prevented on the location of joint via local reduction of beam section near the column and the place of plastic hinge is being transferred from connection to a section of a beam near to the column. A special ilk of RBS connection which is named dogbone connection and its beam wings are cut from a circle in an arcuate form, has displayed a desirable performance against to the seismic loads. This paper aims at obtaining the best cutting geometry of the beam wing in order to improve the performance of the connection against to the seismic loads. For this purpose in this research, we have opted a several panel zone with different dimension on the beam wing under the influence of the seismic loads in Finite Element software called Abaqus along with a cyclic loading, modeled displacement control index and the best sample of cutting dimension among from the samples that are modeled.
\end{abstract}

Keywords: Reduced Beam Section (RBS) Connection, Dogbone Connection, Optimal Geometry, Cyclic Loading, Finite Element Analysis (FEA). 


\section{Introduction}

Following the 1994 Northridge earthquake, a significant amount of research activity was initiated on the behavior of fully restrained steel connections. Much of the research has focused on the Reduced Beam Section (RBS) moment connection. The RBS connection utilizes a circular radius cut in both top and bottom flanges to reduce the flange area and therefore the plastic moment capacity over a length of the beam near the ends of the beam span. This connection was developed to assure greater reliability of steel beam-to-column connections [1].

During the recent decades, a wide range of researches and studies have focused on the RBS connections, these studies include: a bulky research has been done by SAC in 1999 which promulgated that 45 samples of RBS connection was analyzed and tested. In the second research phase of SAC, 17 laboratory samples of RBS connection with real world dimension was tested [2]. Moreover, Chi B and Uang C.M[3] and Zhang $X$ and Ricles J.M [4] conducted full scale laboratory studies inorder to evaluate the seismic behavior of the RBS connections withdeep beams. Anotherresearch was done on the seismic performance of the steel moment frames with weakened connections by Kitjasateanphun[5], Shen J. and Kitjasateanphun T. and Srivanich W T. and Shen J. and Srivanich W. and Hao H [6],Jin J. and El-Tawil S [7],Swati Ajay Kulkarni, GaurangVesmawala[8]and National Institute of Technology and Standard [9,10]. All of the mentioned researches indicate the high ductility and plastical rotation of the dogbone connection and connection preservation and waste of energy can be realized through the creation plastic hinge at the narrowed region.

The purpose of this article is to fulfill a parametric analysis on the RBS connection. The pros and cons of this connection and its behavior in the pseudo seismic reciprocating loading were also assessed. So, the step by step changes of the local cutting parameters on the beam for connection creating was noticed and the behavior alterations of the connection originating from the changes of local cutting parameters were presented in a table. Finally, the optimal cutting parameters in the beam will be revealed via studying the information resulting from parametric studies.

\section{Materials and methods}

\subsection{Geometric and Mechanical Specifications of the Models}

For analyses, the Finite Element Analysis software called Abaqus was used [11]. We have used A36 with yield strength of $2400 \mathrm{~kg} / \mathrm{cm}^{2}$ and final resistance of $3700 \mathrm{~kg} / \mathrm{cm}^{2}$ steel for steel cross-sections. The steel behavior was the model via utilization of von mises yield metric and by considering the non-linear behavior of the material with a Poisson ratio of 0.3.A three line steel curve with kinematic hardening was also used. The performance of the samples in these analyses was compared with each other to determine the ideal design on the basis of the aforementioned metrics.

\subsection{Models Designation}

A RBS connection with radial cut is presented in figure 1.

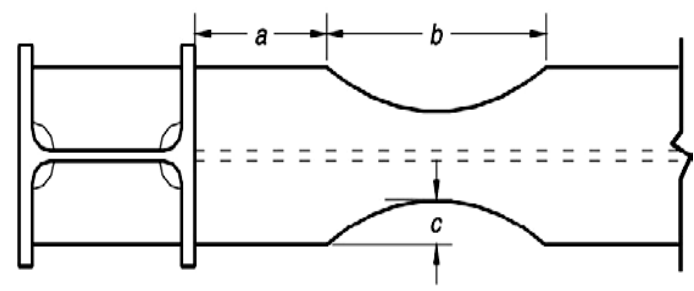

Figure 1: Dogboneconnection along with its cutting parameters

The cutting parameters are as followings:

a indicates the cutting distance from the edge of the column

$\mathrm{b}$ indicates the cutting action region

$c$ indicates the cutting depth

All of the samples are considered in the form of a cantilever beam with a section of IPE 400 and a length of $2.5 \mathrm{~m}$ from the edge of the column and they are made rigid to the beam middle with a section of IPB 360 and Height of 3 
$\mathrm{m}$. From one side the column is hinged and from the other side it isaroller bearing column. The beam sections and the utilized column in the parametric analysis are considered to be constant. In order for lateral bracing of the beam and limiting its capability of movement in the direction of up and down within an imaginary vertical plane, a lateral bracing was applied to the beam with a distance of $1.5 \mathrm{~m}$ from the column edge [12]. According to the AISC and FEMA regulations, in the assumed connection there was a need for continuity sheets head-on the beam wings and these sheets were considered equal to the beam wings with a little width and height conservation (13,14 and 15). According to the studies of Moslahi Tabaret [16], The behavior of the connection with balanced panel zone is appropriate. There exists no significant difference between final resistance cutting and available cutting at the panel zone. That is, the ratio of final cutting resistance to the available cutting is close to 1 . Hence, the thickness of the panel zone will be assumed in a manner that all of the connective samples to be balanced with the panel zone.

\subsection{Loading Features on the Samples}

In this study, a cyclic loading with displacement control in accordance with the Steel Elements Cyclic Loading ATC-24 Regulation [17] was applied on the samples. The detailed specifications of the loading are presented in table 1.

Table 1 - The Applying Procedure of Displacement of Beam end

\begin{tabular}{cccc}
\hline $\begin{array}{c}\text { Load } \\
\text { step } \\
\#\end{array}$ & $\begin{array}{c}\text { Total inter- } \\
\text { story Drift } \\
\text { angle } \\
\left(\text { radian } \times 10^{-3}\right)\end{array}$ & $\begin{array}{c}\text { Number } \\
\text { of load } \\
\text { cycles }\end{array}$ & $\begin{array}{c}\text { Beam end } \\
\text { Displacement } \\
(\mathrm{mm})\end{array}$ \\
\hline 1 & $0 / 375$ & 6 & $\pm 9 / 4$ \\
\hline 2 & $0 / 5$ & 6 & $\pm 12 / 5$ \\
\hline 3 & $0 / 75$ & 6 & $\pm 18 / 7$ \\
\hline 4 & 1 & 4 & \pm 25 \\
\hline 5 & $1 / 5$ & 2 & $\pm 37 / 5$ \\
\hline 6 & 2 & 2 & \pm 50 \\
\hline 7 & 3 & 2 & \pm 75 \\
\hline 8 & 4 & 2 & \pm 100 \\
\hline 9 & 5 & 2 & \pm 125 \\
\hline 10 & 6 & 2 & \pm 150 \\
\hline
\end{tabular}

It should be noted that, the main purpose of using the RBS connection is to efface the tension concentration from panel zone. In this study, fist we will categorize the resulted information of each analysis based on their importance. This categorization is as following:

1. The success of effacing tension concentration from panel zone and beam to column connection and minimum of local buckling of wing and lateral torsional buckling of the beam

2. The capability of wasting the energy of loads (in the form of total area beneath the load-displacement curves in the loading cycles). The main reason of this definition is due to the importance of the energy wasting rate and earthquake forces dissipation in the structures that are under the influence of the Reciprocating dynamic loads.

3. A high primary hardness in the loaddisplacement diagram resulted from sample analysis

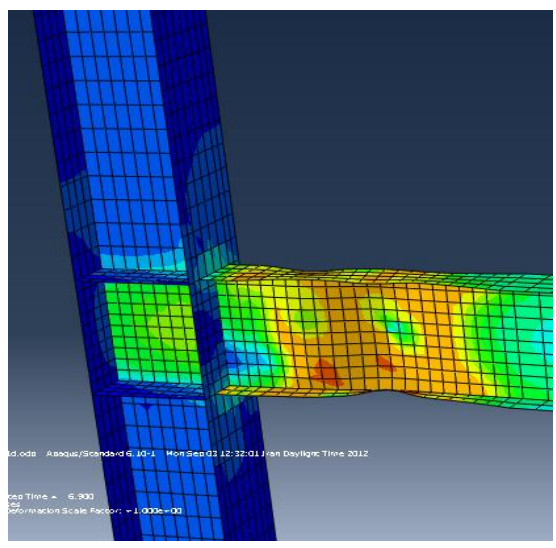

(a)

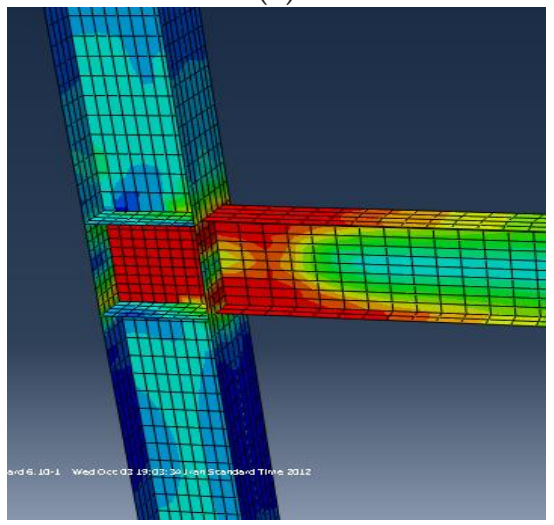

(b)

Figure 2: Three-dimensional von mises tension graph within the $150 \mathrm{~mm}$ displacement at the end of the beam

(a): column to beam simple 
connection

(b): a connection with a radial cut on the beam win with optimal cutting parameters

\subsection{Validation}

A laboratory sample model from a reference of 1 was remodeled and reloaded using the Finite Element Analysis (FEA) in the same way as reference 1 . It is worth noting that we observed the same results in our modeling as the results of the reference, for the sample of the reference. In Figure 4, which displaying the loaddisplacement diagrams of the beam end for the mentioned sample and its results of Finite Element Analysis are presented in our survey.

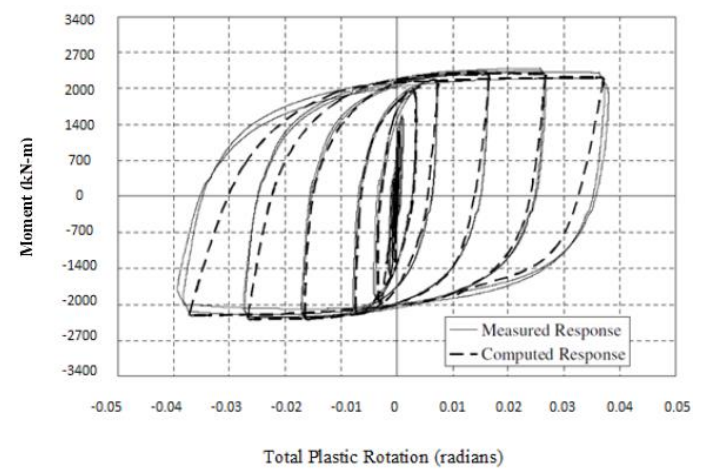

(a)

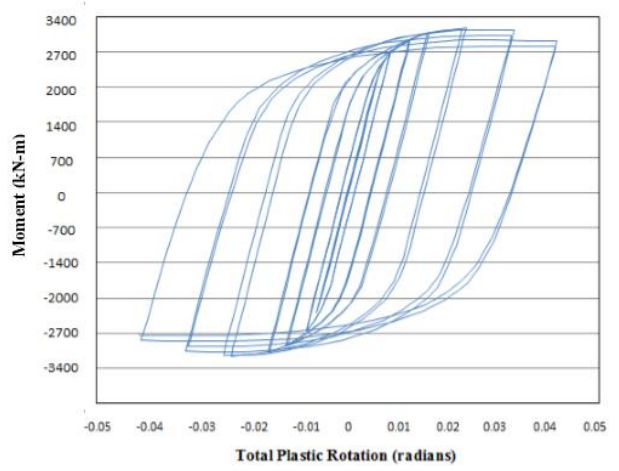

(b)

Figure 3: load-displacement diagram of beam end which is obtained from (a) reference sample

(b) an analyzed sample by Abaqus

\section{Numerical Study}

The different values of the parameters $(a, b, c)$ and their ranges for modeling was determined in order to opt the optimal connection, these values and corresponding ranges are presented in the following table:
Table2 - Cutting parameters

\begin{tabular}{ccccc}
\hline \hline $\begin{array}{l}\text { Parameters value during the } \\
\text { samples modeling }\end{array}$ & $\begin{array}{l}\text { Cutting } \\
\text { parameters }\end{array}$ \\
\hline $\mathrm{d} \quad 0.75 \mathrm{~d}$ & $0.5 \mathrm{~d}$ & $0.25 \mathrm{~d}$ & 0 & $\mathrm{a}$ \\
\hline $2 \mathrm{~d}$ & $1.5 \mathrm{~d}$ & $\mathrm{~d}$ & $0.5 \mathrm{~d}$ & $\mathrm{~b}$ \\
\hline & $0.1 \mathrm{~d}^{1}$ & & & $\mathrm{c}$ \\
\hline
\end{tabular}

\subsection{Evaluation of results of the samples analysis}

We used the $\lambda^{2}$ parameter to display the qualitative criteria of plastic hinge distance from the panel zone in a quantitative form. This

Table 3 - The analysis results of first 20 samples

\begin{tabular}{|c|c|c|c|c|c|}
\hline Row & $\mathrm{a}$ & b & $\begin{array}{c}\text { Energy } \\
\text { Dissipation } \\
\mathrm{J}\end{array}$ & $\begin{array}{l}\text { Tension } \\
\text { status on } \\
\text { the panel } \\
\text { zone }(\lambda)\end{array}$ & $\begin{array}{c}\text { Primary } \\
\text { Hardness of } \\
\text { load- } \\
\text { displacement } \\
\text { diagram } \\
(\mathrm{N} / \mathrm{m}) \\
\end{array}$ \\
\hline 1 & 0 & $0.5 \mathrm{~d} 0.1 \mathrm{~d}$ & 299705 & $82 / 7$ & 5396 \\
\hline 2 & 0 & d $\quad 0.1 \mathrm{~d}$ & 290453 & $85 / 33$ & 5235 \\
\hline 3 & 0 & $1.5 \mathrm{~d} 0.1 \mathrm{~d}$ & 284730 & $89 / 4$ & 5102 \\
\hline 4 & 0 & $2 \mathrm{~d} \quad 0.1 \mathrm{~d}$ & 280224 & 90 & 4998 \\
\hline 5 & $0.25 \mathrm{~d}$ & $0.5 \mathrm{~d} 0.1 \mathrm{~d}$ & 308688 & 86 & 5405 \\
\hline 6 & $0.25 \mathrm{~d}$ & $\mathrm{~d} \quad 0.1 \mathrm{~d}$ & 293615 & 85 & 5266 \\
\hline 7 & $0.25 \mathrm{~d}$ & $1.5 \mathrm{~d} 0.1 \mathrm{~d}$ & 288922 & $89 / 8$ & 5145 \\
\hline 8 & $0.25 \mathrm{~d}$ & $2 \mathrm{~d} \quad 0.1 \mathrm{~d}$ & 288817 & 90 & 5052 \\
\hline 9 & $0.5 \mathrm{~d}$ & $0.5 \mathrm{~d} 0.1 \mathrm{~d}$ & 313395 & 86 & 5429 \\
\hline 10 & $0.5 \mathrm{~d}$ & d $0.1 \mathrm{~d}$ & 295188 & $88 / 8$ & 5300 \\
\hline 11 & $0.5 \mathrm{~d}$ & $1.5 \mathrm{~d} 0.1 \mathrm{~d}$ & 295094 & $89 / 5$ & 5192 \\
\hline 12 & $0.5 \mathrm{~d}$ & $2 \mathrm{~d} \quad 0.1 \mathrm{~d}$ & 290057 & $89 / 5$ & 5108 \\
\hline 13 & $0.75 \mathrm{~d}$ & $0.5 \mathrm{~d} 0.1 \mathrm{~d}$ & 327337 & $83 / 5$ & 5451 \\
\hline 14 & $0.75 d$ & $\mathrm{~d} \quad 0.1 \mathrm{~d}$ & 306939 & 83 & 5334 \\
\hline 15 & $0.75 d$ & $1.5 \mathrm{~d} 0.1 \mathrm{~d}$ & 290790 & 90 & 5237 \\
\hline 16 & $0.75 \mathrm{~d}$ & $2 \mathrm{~d} \quad 0.1 \mathrm{~d}$ & 324476 & $85 / 9$ & 5162 \\
\hline 17 & d & $0.5 \mathrm{~d} 0.1 \mathrm{~d}$ & 331089 & 78 & 5213 \\
\hline 18 & d & d $\quad 0.1 \mathrm{~d}$ & 311906 & $86 / 7$ & 5368 \\
\hline 19 & $\mathrm{~d}$ & $1.5 \mathrm{~d} 0.1 \mathrm{~d}$ & 328779 & $86 / 6$ & 5280 \\
\hline 20 & $\mathrm{~d}$ & $2 \mathrm{~d} \quad 0.1 \mathrm{~d}$ & 333605 & $82 / 4$ & 4967 \\
\hline
\end{tabular}

criterion is being used as an assessment and judgment metric for tension concentration on the panel zone. To put it simpler, there is a reverse relation between tension elements and $\gamma$; the low 
tension element implies the high $\lambda$ which indicates the proper and positive performance of the connection. Since the value of the criteria for judgment of the connection performance quality are not the same, for performance evaluation of the samples we should weight the criteria. Hence, we assigned weight ratio of 3 to energy dissipation criteria since of its high importance for performance evaluation of the samples, and 2 was allocated to Index of Plastic hinge distance from the panel zone since of its $2^{\text {nd }}$ position within the priority and primary hardness of load-displacement diagram was weighted with 1.

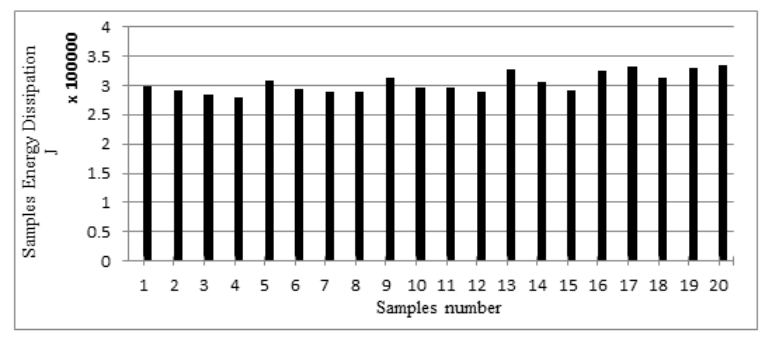

Figure 4 - The comparison of Energy dissipation of the samples

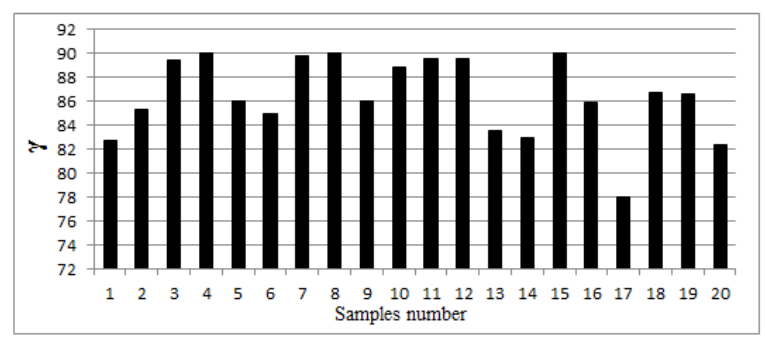

Figure 5 - Plastic hinge distance from panel zone $(\gamma)$

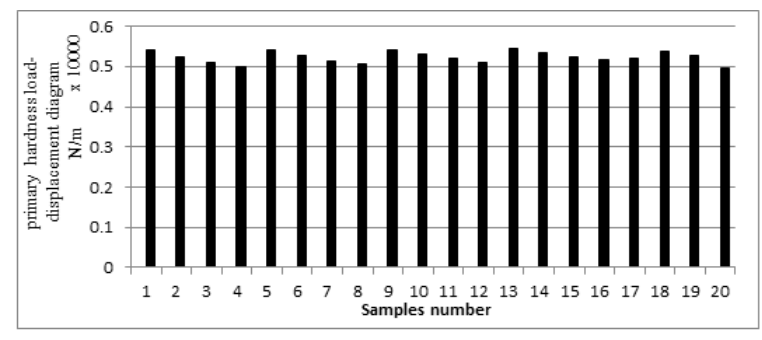

Figure 6 - The comparison of primary hardness load-displacement diagram

\subsection{Fragmentizing the incremental steps} for the sample with the best performance

In this section, in order to increase the Accuracy of the study the incremental steps of the parameters will be fragmented and possible optimal points near the sample will be identified and compared to the other samples. Therefore, the value of the $a, b$ and c related to the sample 19 will increase and decreased around the each parameter optimal value, respectively, and the resulted values will be combined with each other.

Table 4 - The comparison of samples performance around the sample 19

Cutting

parameters

\begin{tabular}{ccc}
\hline $1.125 d$ & $0.875 d$ & $A$ \\
\hline $1.75 d$ & $1.25 d$ & $B$ \\
\hline $0.15 d$ & $0.05 d$ & $C$
\end{tabular}

Table 5 - The comparison of samples performance around the sample 19

\begin{tabular}{ccccccc}
\hline \hline Row & a & b & c & $\begin{array}{c}\text { Energy } \\
\text { Dissipation } \\
\text { J }\end{array}$ & $\begin{array}{c}\text { Tension } \\
\text { status on the } \\
\text { panel zone } \\
(\lambda)\end{array}$ & $\begin{array}{c}\text { Primary } \\
\text { Hardness of } \\
\text { load- } \\
\text { displacement } \\
\text { diagram } \\
(\mathrm{N} / \mathrm{m})\end{array}$ \\
\hline 21 & $0.875 \mathrm{~d}$ & $1.5 \mathrm{~d}$ & $0.1 \mathrm{~d}$ & 301256 & $89 / 4$ & 5259 \\
\hline 22 & $1.125 \mathrm{~d}$ & $1.5 \mathrm{~d}$ & $0.1 \mathrm{~d}$ & 329594 & $81 / 7$ & 5302 \\
\hline 23 & $\mathrm{~d}$ & $1.25 \mathrm{~d}$ & $0.1 \mathrm{~d}$ & 318303 & $87 / 43$ & 5321 \\
\hline 24 & $\mathrm{~d}$ & $1.75 \mathrm{~d}$ & $0.1 \mathrm{~d}$ & 329807 & $86 / 5$ & 5245 \\
\hline 25 & $\mathrm{~d}$ & $1.5 \mathrm{~d}$ & $0.05 \mathrm{~d}$ & 349214 & $71 / 1$ & 5525 \\
\hline 26 & $\mathrm{~d}$ & $1.5 \mathrm{~d}$ & $0.15 \mathrm{~d}$ & 231002 & 90 & 4926 \\
\hline
\end{tabular}

With regard to the table 3 , it is clear that sample 24 with cutting parameters of $(a=d, b=1.75 d, c=0.1 d) \quad$ possesses the best performance among the samples around the sample 19. Now, the sample 19 will be compared with sample 24 and the sample with beam to column simple connection (without cut) to determine the final result (the sample with optimum cutting) and the selected sample as the outcome of the research. 
Table 6 - the comparison of sample 24 with samples around it and the sample with simple connection (without cutting)

\begin{tabular}{|c|c|c|c|c|c|c|}
\hline Row & $\mathrm{a}$ & b & c & $\begin{array}{c}\text { Energy } \\
\text { Dissipation } \\
\mathbf{J}\end{array}$ & $\begin{array}{l}\text { Tension } \\
\text { status on } \\
\text { the panel } \\
\text { zone }(\lambda)\end{array}$ & $\begin{array}{c}\text { Primary } \\
\text { Hardness of } \\
\text { load- } \\
\text { displaceme } \\
\text { nt diagram } \\
(\mathrm{N} / \mathrm{m})\end{array}$ \\
\hline 19 & $1.125 \mathrm{~d}$ & $1.75 \mathrm{~d}$ & $0.1 \mathrm{~d}$ & 334208 & 80 & 5269 \\
\hline 28 & $0.875 \mathrm{~d}$ & $1.75 \mathrm{~d}$ & $0.1 \mathrm{~d}$ & 322178 & $88 / 6$ & 5171 \\
\hline 29 & $\mathrm{~d}$ & $1.5 \mathrm{~d}$ & $0.1 \mathrm{~d}$ & 328779 & $86 / 6$ & 5280 \\
\hline 24 & $\mathrm{~d}$ & $1.75 \mathrm{~d}$ & $0.1 \mathrm{~d}$ & 329807 & $86 / 5$ & 5245 \\
\hline 27 & Witho & ut RBS & S cut & 366337 & 66 & 5430 \\
\hline
\end{tabular}

It is evident that samples 19 and 24 have a somehow identical performance, but the performance of sample 24 is a little better than the sample 19. Thus, the sample 24 has the best sample among other ones.

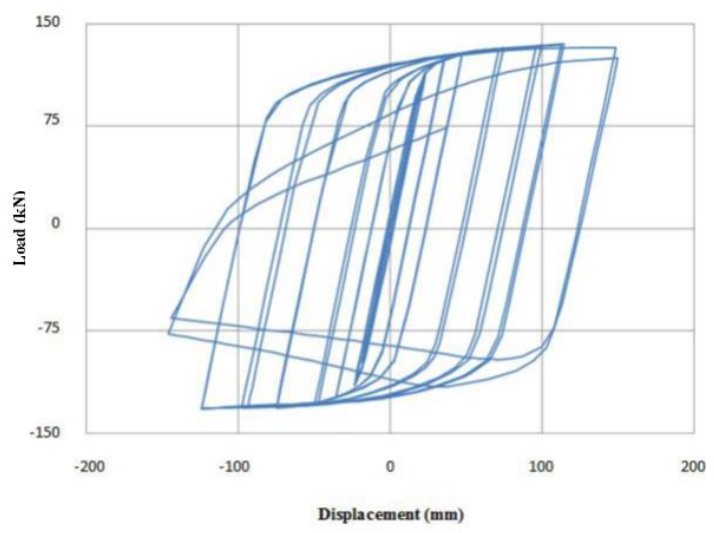

(a)

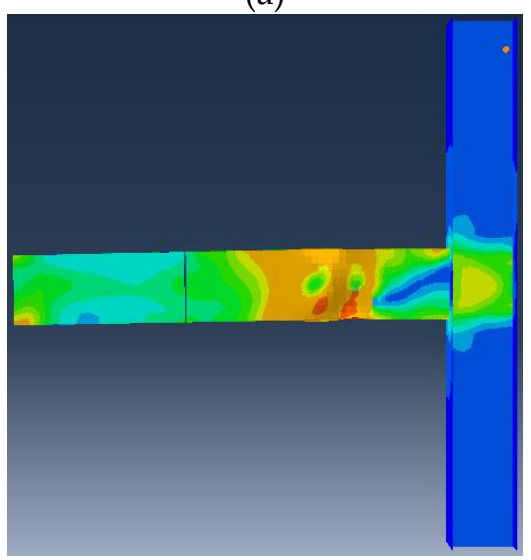

(b)

(a): load-displacement diagram of the sample with optimal cutting parameters

(b): von mises stress distribution within the $150 \mathrm{~mm}$ displacement of the free end point of the beam

Figure 7: The behavioral properties of the sample with optimum parameters (Sample 24)

\subsection{Evaluation of samples performance using two-story frame models}

All the samples that were modeled so far, were based on the assumption that the location of plastic hinge formation is located in the middle of the beam and column length for moment frames. However, in the real world, it is different since of the fact that the rigidity of the column base leads to the formation of the hinge a little above the middle of the column. So, in order to consider a deviation from real world cases during the theoretical modeling, a number of samples with best performance in terms of considered metrics have been remodeled in the form of two-story frames with a nozzle that are similar to the original shape of the structures. The procedures of the modeling and loading are similar to the previous procedures that are applied on the samples. The result of this modeling is provided in table 7.

Table 7 - The results of analysis of samples with two-story frame model

\begin{tabular}{|c|c|c|c|c|c|c|}
\hline Row & $\mathrm{a}$ & b & c & $\begin{array}{c}\text { Energy } \\
\text { Dissipation } \\
\mathrm{J}\end{array}$ & $\begin{array}{l}\text { Tension } \\
\text { status } \\
\text { on the } \\
\text { panel } \\
\text { zone } \\
(\lambda)\end{array}$ & $\begin{array}{c}\text { Primary } \\
\text { Hardness of } \\
\text { load- } \\
\text { displacement } \\
\text { diagram } \\
(\mathrm{N} / \mathrm{m}) \\
\end{array}$ \\
\hline 1 & $\mathrm{~d}$ & $1.5 \mathrm{~d}$ & $0.1 \mathrm{~d}$ & 2816381 & $7 / 27$ & 39848 \\
\hline 2 & $0.75 \mathrm{~d}$ & $0.5 \mathrm{~d}$ & $0.1 \mathrm{~d}$ & 2857311 & $8 / 34$ & 39165 \\
\hline 3 & $0.75 \mathrm{~d}$ & $2 d$ & $0.1 \mathrm{~d}$ & 2781607 & $8 / 84$ & 38749 \\
\hline 4 & $\mathrm{~d}$ & $2 \mathrm{~d}$ & $0.1 \mathrm{~d}$ & 2761963 & $9 / 25$ & 38849 \\
\hline 5 & $\mathrm{~d}$ & $0.5 \mathrm{~d}$ & $0.1 \mathrm{~d}$ & 2769275 & $9 / 42$ & 37511 \\
\hline 6 & $\mathrm{~d}$ & $1.75 \mathrm{~d}$ & $0.1 \mathrm{~d}$ & 2973628 & $9 / 27$ & 38877 \\
\hline 7 & & $\begin{array}{l}\text { hout } R \\
\text { cut }\end{array}$ & & 2973628 & 3 & 39058 \\
\hline
\end{tabular}

With regard to the table 5 , the sample which have cutting parameters of $(a=d, b=1.75 d, c=0.1 d)$ is the best one from a performance perspective. This result is completely in complying with the results of the proceeding steps.

\section{Results and discussion}

According to samples analysis results, it can be deduced that by increasing the value of a 
parameters, the energy dissipation rate of the study sample will also increase. The main reason of such condition is the distance of the RBS region from the panel zone, which causes the augmentation of hardness of a region of beam to column connection and the increase of energy dissipation should be expected. But from two other criteria perspective, the results indicate that these metrics are depended on $a, b$ and $c$ parameters and we are unable to define a logical process for their response against the cutting parameters changes.

With regard to the mentioned points linked to the acceptance metrics of the an optimal connection, it was observed that the sample 19 has with cutting parameters of $(a=d, b=1.5 d, c=0.1 d)$ has the best performance among the 20 modeled sample.

In order to boost the accuracy of the research for achieving the optimal cutting parameters, the incremental steps of the parameters around the sample 19 were fragmented, then we modeled them. The results of these samples analysis are provided in table 3. As it can be inferred from this table, sample 24 with cutting parameters of $(\mathrm{a}=\mathrm{d}, \mathrm{b}=1.75 \mathrm{~d}, \mathrm{c}=0.1 \mathrm{~d})$ has the best performance among the available samples of the table. With regard to the fact that, the periphery of this sample was considered during the modeling and the suggested dimensions for cutting should be feasible and practical, so we didn't fragmentize the incremental steps and the sample 24 has the best cutting parameters and is the final result of the research.

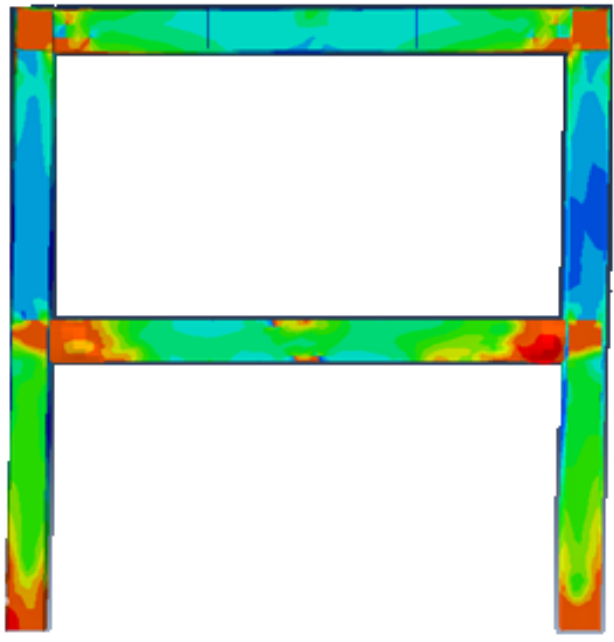

(a)

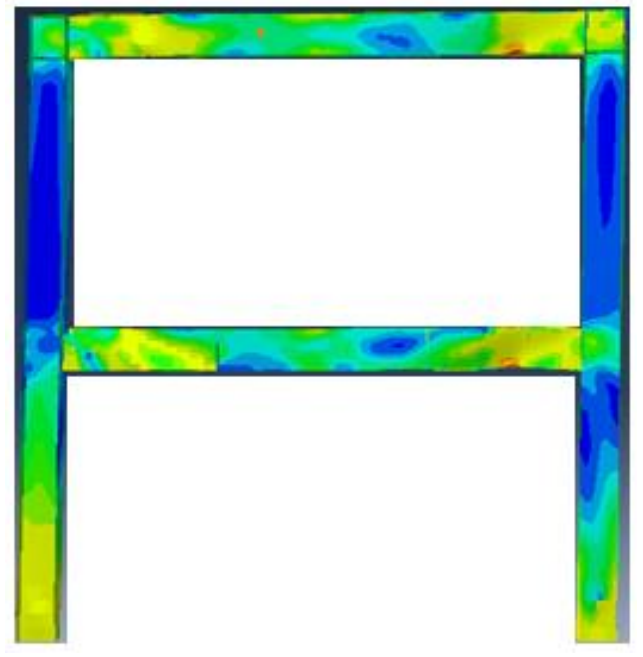

(b)

(a): a sample with optimum RBS connection

(b): a sample with beam to column simple connection

Figure 8: Samples with RBS and beam to column simple connections

\section{References}

[1] Scott MA,Lowrence DR. (2004). The reduced beam section moment connection without continuity plates. $13^{\text {th }}$ world conference on earthquake engineering, Vancouver, BC, Canada. August 1-6, paper No. 1504.

[2] FEMA 355D, (2000). State of the art report on connection performance. Prepared by the SAC Joint Venture for the Federal Emergency Management Agency. Washington, DC.

[3] Chi B,Uang.M. (2002). Cyclic Response and Design Recommendations of Reduced Beam Section Moment Connections with Deep Columns. Journal of Structural Engineerig.Vol. 128, No. 4, pp. 464-473.

[4] Zhang X,Ricles JM. (2006). Experimental Evaluation of Reduced Beam Section Connections to Deep Columns. Journal of Structural Engineering.Vol. 132,No. 3, pp. 346-357.

[5] Shen J,Kitjasateanphun T,Srivanich W. (2000). Seismic performance of steel moment 
frames with reduced beam sections. Engineering Structures.Vol. 22, pp. 968-983.

[6] Kitjasateanphun T,Shen J,Srivanich W,Hao H. (2001). Inelastic Analysis of Steel Frames with Reduced Beam Section. Structural Design of Tall Building.Vol. 10, pp. 231-244.

[7] Jin J. El-Tawil S. (2005). Seismic performance of steel frames with reduced beam section connections. Journal of Constructional Steel Research.Vol. 61, pp. $453-471$

[8] Swati AK, Gaurang V.(2014). Study of steel moment connection with and without reduced beam section.

[9] NEHRP Seismic Design Technical Brief. (2009). Seismic Design of Steel Special Moment Frame - A Guide for Practicing Engineers, USA, No. 2.

[10] NIST GCR 11-917-13. (2011). Research Plan for the Study of Seismic Behavior and Design of Deep, Slender Wide Flange Structural Steel Beam-Column Members. NIST, USA.

[11] Abaqus, version 6.14 -1. User's manual.

[12] AISC. (2002). Seismic Provisions for Structural Steel Buildings, American Institute of Steel Construction. Chicago, Illinois.

[13] ANSI/AISC 341-10. (2010). Seismic provisions for Structural Steel Buildings, American Institute of Steel Construction. USA.

[14] ANSI/AISC 360-10. (2010). Specification for Structural Steel Buildings, American Institute of Steel Construction USA.
[15] FEMA-350. (2000). Recommended Seismic Design Criteria for New Steel Moment Frame Buildings. Federal Emergency Management Agency. Washington DC, USA.

[16] Deylami A. MoslehiTabar A. (2008). Experimental study on the key issues affecting cyclic 8ehavior of reduced beam section moment connections. The 14thWorld Conference on Earthquake Engineering. Beijing, China. October 12-17.

[17] ATC-24. (1992). Guidelines for Cyclic Seismic Testing of Components of Steel Structures for Buildings. Report No. ATC-24, Applied Technology Council, Redwood City, CA. 